DOI: 10.12957/demetra.2018.32911

\title{
Rotulagem e promoção comercial de fórmulas infantis comercializadas no Brasil
}

\section{Labeling and commercial promotion of infant formulas retailed in Brazil}

Mariana Morais Baldani'

Grazieli Benedetti Pascoal ${ }^{1}$

Ana Elisa Madalena Rinaldi ${ }^{1}$

1 Universidade Federal de Uberlândia, Faculdade de Medicina, Curso de Nutrição. Uberlândia, MG, Brasil.

Correspondência / Correspondence Ana Elisa Madalena Rinaldi

E-mail: anaelisarinaldi@gmail.com

\section{Resumo}

Objetivo: Analisar a conformidade da rotulagem e a promoção comercial às legislações vigentes de fórmulas infantis comercializadas no Brasil. Metodologia: Foram analisados 32 produtos de quatro marcas comerciais de fórmulas infantis para lactentes $(n=15)$, de seguimento para lactentes $(n=4)$ e de crianças de primeira infância $(n=13)$. Os produtos foram analisados segundo às Resoluções da Diretoria Colegiada (RDC) 222/2002, 259/2002, 360/03, 42/2011, 43/2011, 44/2011 e 46/2011; Norma Brasileira de Comercialização de Alimentos para Lactentes e Crianças de Primeira Infância, Bicos, Chupetas e Mamadeiras (NBCAL); Portaria 157/2002; Decreto 986/1969 e Leis 10.674/2003, 11.265/2006, 11.474/2007. As inconformidades foram expressas em frequências relativas. Resultados: Foram identificadas inconformidades em $34,7 \%$ das fórmulas, sendo $43,7 \%$ quanto às exigências de rotulagem geral e $56,2 \%$, quanto à promoção comercial. A respeito da rotulagem geral, 28,1\% dos produtos apresentaram erros na informação nutricional e 21,8\% na designação do produto. Quanto à promoção comercial, todas $(100 \%)$ as fórmulas infantis apresentaram não conformidades à venda mercantil. Adicionalmente, em 40,6\% dos produtos foram observadas ilustrações inadequadas; em $65,6 \%$ foram identificadas as palavras "Premium" e "Supreme" que podem indicar semelhança com o leite materno; em $93,7 \%$ dos produtos foram identificadas frases que dão falso conceito de vantagem e/ ou segurança. Outras irregularidades foram quanto à composição nutricional $(3,1 \%)$, indicações de saúde $(6,2 \%)$ e uso inadequado de alegações nutricionais $(68,7 \%)$. Conclusões: Os resultados indicam o cumprimento da NBCAL pelas indústrias no que tange 
à rotulagem nutricional, porém há necessidade de adequação no critério promoção comercial e principalmente reforço na fiscalização pelos órgãos responsáveis.

Palavras-chave: Rotulagem de alimentos. Fórmulas infantis. Aleitamento materno.

\section{Abstract}

Objective: This study aimed to analyze the conformity of labeling and commercial promotion with the current legislation on infant formulas marketed in Brazil. Methodology: Thirty two labels of four different brands of infant formula $(n=15)$, follow-on formula $(\mathrm{n}=4)$ and toddler formula $(\mathrm{n}=13)$ were analyzed. The labels were checked according to the Collegiate Discharge Resolution (RDC) 222/02, 259/02, 360/03, 42/11, 43/11, 44/11 and 46/11; Brazilian Norm for Commercialization of Food for Infants and Young Children, Nipples, Pacifiers and Baby Bottles (NBCAL, acronym in Portuguese) ; Rule 157/02; Decree 986/69 and Laws 10,674/03, 11,265/06, 11,474/07. Results: Nonconformities were identified in $34.7 \%$ of the formulas, $43.7 \%$ for general labeling requirements and $56.2 \%$ for commercial promotion. Concerning general labeling, $28.1 \%$ of products presented irregularities in nutritional information, and $21.8 \%$ in the product designation. Regarding commercial promotion, all (100\%) infant formulas showed nonconformities to commercial sale. In addition, inadequate illustrations were observed in $40.6 \%$ of the products ; in $65.6 \%$ the words "Premium" and "Supreme" were identified which may indicate similarity with breast milk; and $93.7 \%$ of the products identified phrases that give false concept of advantage and / or safety. Other non-conformities were related to nutritional composition (3.1\%), health indications (6.2\%), and inadequate use of nutrition allegations $(68.7 \%)$. Conclusions: The results indicate the compliance of NBCAL by the industries as to nutritional labeling. However, there is the necessity to adequate commercial promotion criteria and reinforce mainly the supervision by the responsible organs.

Keywords: Food labeling. Commerce. Infant formula. Breastfeeding. 


\section{Introdução}

Nos anos 1970, as taxas de desmame precoce, desnutrição e mortalidade infantis aumentaram, ${ }^{1}$ principalmente em função do intenso uso de fórmulas infantis. Paralelamente, nessa década, a Organização Mundial da Saúde (OMS) e o Fundo das Nações Unidas para a Infância (UNICEF) recomendaram o aleitamento materno para promoção à saúde e atenção à nutrição infantil devido às diversas evidências da proteção do aleitamento às doenças diarreicas e desnutrição infantil. ${ }^{2}$ Em 1981, a OMS também elaborou o Código Internacional de Comercialização de Substitutos do Leite Materno e incentivou os países signatários a elaborarem códigos a fim de conter a propaganda excessiva das indústrias e proteger as mães de informações que as desencorajassem de amamentar. ${ }^{2}$

No Brasil, em função das baixas taxas de aleitamento materno e divulgação de seus benefícios à sociedade, as ações pró-aleitamento materno tiveram início em 1980, com destaque do Programa Nacional de Incentivo ao Aleitamento Materno (PNIAM), ${ }^{3}$ em 1981; e à Norma para Comercialização de Alimentos para Lactentes (NCAL), ${ }^{4}$ em 1988. A partir de 2002, os bicos, chupetas e mamadeiras foram inseridos no escopo da NCAL, passando a ser denominada "Norma Brasileira de Comercialização de Alimentos para Lactentes e Crianças de Primeira Infância, Bicos, Chupetas e Mamadeiras". ${ }^{4}$ A NBCAL define-se como "um conjunto de normas que regula a promoção comercial e a rotulagem de alimentos e produtos destinados a recém-nascidos e crianças de até 3 anos de idade, como leites, papinhas, chupetas e mamadeiras", cujo objetivo é assegurar o uso apropriado desses produtos de forma que não haja interferência na prática do aleitamento materno. ${ }^{5}$

Desta forma, a NBCAL passou a ser regulamentada pelas Portarias $2.051(08 / 11 / 2001),{ }^{6} \mathrm{RDC}$ 221(05/08/2002) $)^{7}$ e RDC 222 (05/08/2002). ${ }^{5,8}$ Posteriormente, em 2006, foi elaborada a Lei 11.265 (03/01/2006), ${ }^{9}$ mas sancionada somente em 2015. A Lei 11.265 regulamenta a comercialização de alimentos para lactentes e crianças de primeira infância e também a de produtos de puericultura correlatos. ${ }^{9}$

A Rede Internacional em Defesa do Direito de Amamentar (International Baby Food Action Network - IBFAN), fundada em 1979 e com sede no Brasil em 1983, também foi criada para proteger e incentivar o aleitamento materno e alertar sobre riscos do uso de fórmulas infantis na infância. Ademais, a IBFAN fiscaliza a execução do Código Internacional de Comercialização de Substitutos do Leite Materno e as legislações envolvidas..$^{10}$ A IBFAN Brasil monitora o cumprimento da NBCAL ${ }^{10}$ e há mais de duas décadas essas legislações, muita das vezes, são desobedecidas pela comercialização de leites artificiais.

A situação atual do Código Internacional de Substitutos do Leite Materno em diversos países signatários da OMS está reunida em uma publicação também da OMS, ${ }^{11}$ apontando, principalmente, 
a diversidade de produtos que estão sob esta regulamentação, seu formato legal e a faixas etárias para as quais os produtos infantis são destinados e consequentemente regulamentados.

No Brasil, a NBCAL tem caráter de Lei desde 2015, sendo relevante verificar a situação dos rótulos das fórmulas infantis quanto às especificações legais. Este trabalho tem como objetivo analisar a conformidade da rotulagem e a promoção comercial de fórmulas infantis frente às legislações brasileiras vigentes.

\section{Métodos}

Este estudo foi transversal, cujo objeto de análise constituiu rótulos das fórmulas infantis para lactentes saudáveis. A visualização dos rótulos dos produtos foi realizada em 12 estabelecimentos comerciais (varejista e/ou atacado) localizados em Uberlândia (Minas Gerais) entre os meses de abril a agosto de 2016 .

O estudo foi desenvolvido em duas fases: a primeira constituiu em fazer o levantamento de todas as fórmulas infantis para lactentes saudáveis comercializadas no Brasil nos websites das empresas responsáveis pela sua fabricação. Nesta fase, foram identificadas quatro empresas responsáveis pela fabricação das fórmulas para lactentes saudáveis. A segunda fase constituiu na análise de conformidade dos rótulos frente à legislação vigente, no que tange à rotulagem geral, à rotulagem nutricional e à promoção comercial.

Segundo as legislações específicas ${ }^{12-14}$ sobre esse tema, as fórmulas infantis são classificadas segundo a idade da criança. As "fórmulas infantis para lactentes" são destinadas às crianças de zero a cinco meses completos; as "fórmulas infantis de seguimento para lactentes" são destinadas às crianças com 6 a 11 meses completos e as "fórmulas infantis para crianças de primeira infância" de 12 a 36 meses.

Para a organização das informações presentes nas legislações foram elaboradas duas fichas de checagem, a partir de uma lista de checagem utilizada pela Agência Nacional de Vigilância Sanitária - ANVISA (Quadro 1). Uma lista foi direcionada à análise da "Rotulagem de Fórmulas Infantis para Lactentes" e a outra à "Rotulagem de Fórmulas Infantis de Segmento para Lactentes e Crianças de Primeira Infância”. A promoção comercial foi analisada nos rótulos de todas as fórmulas. 
Quadro 1. Descrição das legislações utilizadas pela ANVISA para regulamentação da rotulagem geral e nutricional e da promoção comercial. Brasil, 2016.

\begin{tabular}{|c|c|}
\hline Rotulagem Geral e Nutricional & Aspectos de Promoção Comercial \\
\hline RDC n. $.92^{12}, 43^{13}, 44^{14}, 46^{15}(19 / 09 / 2011)$ & $\begin{array}{c}\text { RDC n. } .^{\circ} 42^{12}, 43^{13} \text { e } 44^{14} \\
(19 / 09 / 2011)\end{array}$ \\
\hline RDC n. $.927(6 / 08 / 2010)^{16}$ & RDC n. $.222(05 / 08 / 2002)^{8}$ \\
\hline RDC n.o $259(20 / 09 / 2002)^{17}$ & Lei $11.265(03 / 01 / 2006)^{9}$ \\
\hline Item 3.4.1.1.RDC n.o $360(23 / 12 / 2003)^{18}$ & Lei $11.474(15 / 05 / 2007)^{21}$. \\
\hline \multicolumn{2}{|l|}{ Portaria INMETRO n.o 157 (19/08/2002) $)^{19}$} \\
\hline Lei $10.674(16 / 05 / 2003)^{20}$ & \\
\hline
\end{tabular}

De forma sumarizada, a RDC n⿳⺈ 222/2002 ${ }^{8}$ aborda questões de promoção de fórmulas infantis como a existência de expressões que possam induzir o uso desses produtos por um falso conceito de vantagem ou segurança. A RDC no $42 / 2011^{12}$ dispõe sobre o regulamento técnico de compostos de nutrientes para alimentos destinados aos lactentes e às crianças de primeira infância. A RDC n⿳0 43/2011 ${ }^{13}$ dispõe sobre o regulamento técnico para fórmulas infantis para lactentes. A RDC n⿳o $44 / 2011^{14}$ dispõe sobre o regulamento técnico para fórmulas infantis de seguimento para lactentes e crianças de primeira infância. A RDC no $46 / 2011^{15}$ dispõe sobre aditivos alimentares e coadjuvantes de tecnologia para fórmulas infantis destinadas a lactentes e crianças de primeira infância.

Para a análise de conformidade da rotulagem, foram elaboradas planilhas contendo todos os itens de cada lista de checagem. Os itens foram classificados com o valor "0" quando houve conformidade, o valor "1" quando não houve conformidade e "2" quando não se aplicava às resoluções. Desta forma, foi possível sumarizar os resultados da análise de todas as marcas em frequências absolutas e relativas, com o auxílio do software Excel 2010.

\section{Resultados}

Na primeira fase, após acesso aos websites das quatro empresas responsáveis pela fabricação das fórmulas, foram identificadas 47 fórmulas infantis. Em função da indisponibilidade dos rótulos completos nos websites, optou-se por identificar as fórmulas em 12 estabelecimentos comerciais (supermercados e farmácias). Nestes pontos de venda, foram possíveis analisar todas as informações disponíveis nos produtos. Dentre 47 produtos, 15 foram descartados por serem destinados à dietoterapia específica. Desta forma, foram selecionados 32 produtos para análise da sua conformidade às legislações. 
A lista de checagem de rotulagem de fórmulas infantis para lactentes contém 44 itens e a lista de checagem de fórmulas infantis de segmento para lactentes e crianças de primeira infância contém 46 itens (dois itens a mais a respeito do uso de mel nas fórmulas infantis). No que se refere à análise das listas de checagem, $65,2 \%$ dos itens $(\mathrm{n}=30)$ em relação aos produtos estavam em conformidade com a legislação brasileira vigente. Dentre os demais itens $(n=16), 43,7 \%(n=7)$ apresentaram inconformidades quanto às exigências de rotulagem geral e 56,2\% $(\mathrm{n}=9)$ apresentam não conformidades quanto às exigências de promoção comercial.

Quanto às conformidades de rotulagem, regulamento técnico e informação nutricional, todas as fórmulas infantis estavam de acordo com a RDC $\mathrm{n}^{\mathrm{o}} 27 / 2010,{ }^{16}$ a qual exige o registro do produto na ANVISA. O item 3.1.a. da RDC no 259/200217 também foi atendido em todos os rótulos, o qual exige que os alimentos embalados não devem utilizar inscrição, vocábulo ou figura que possa levar o consumidor a erro na escolha do produto.

Adicionalmente, todas as fórmulas se apresentaram em conformidades quanto aos requisitos exigidos para a descrição de conteúdo líquido, identificação de origem, dados dos fabricantes, validade, aditivos alimentares, descrição sobre a forma adequada de armazenamento e conservação do produto, informação sobre a presença do glúten, idioma, se foi fabricado no Brasil ou não e instruções de preparo e manuseio do produto. Todas as fórmulas infantis sem leite ou derivados estavam adequadas no item II do artigo 40 da RDC 43/2011 ${ }^{13}$, o qual exige a presença da advertência no rótulo "não contém leite ou produtos lácteos" ou com frase equivalente conforme a lei. Entretanto, 9,4\% (n=3) das fórmulas não exibiram o número do lote no produto.

As fontes proteicas foram claramente identificadas nos rótulos e a composições nutricionais quanto às gorduras e carboidratos estavam em conformidade à legislação em todas as fórmulas. Nenhuma apresentou gorduras hidrogenadas na composição.

No que tange às legislações da rotulagem geral, 21,8\% ( $\mathrm{n}=7)$ dos produtos não estavam em conformidade quanto à designação do produto. Por exemplo, ao invés de "Fórmula Infantil para Lactente", estava escrito "Fórmula Infantil com Ferro para Lactente".

De acordo com o item 3.4.1.1. da RDC no 360/2003, ${ }^{18}$ a expressão "Informação Nutricional" deve estar com todas as letras em 'caixa alta', porém 28,1\% (n=9\%) produtos de uma mesma marca não cumpriram esse requisito. Somente uma (3,1\%) fórmula apresentou erro quanto à composição de proteína, por ter apresentado um teor inferior a 2,25g de proteína/100 kcal e outra fórmula por ter apresentado valor calórico superior a $70 \mathrm{kcal} / 100 \mathrm{ml}$ de produto pronto, inadequado de acordo com a RDC no $\mathbf{4} / 2011$. $^{13}$

Vinte e dois produtos $(68,8 \%)$ apresentaram as propriedades funcionais de forma irregular. Por exemplo: dois rótulos apresentam o destaque de "Luteína" que não está prevista nas RDC n⿳ำ 
$43^{13}$ e RDC no 44 de 2011. ${ }^{14}$ Dois rótulos (6,3\%) apresentavam frases ou expressões de condições de saúde para os quais os produtos possam ser utilizados o que contraria as leis.

Ademais, o item 4.3.1 da Resolução RDC no 222/2002 e inciso 1 do Artigo 10 da Lei 11.265/2006 proíbem o uso de ilustrações, fotos ou outras representações gráficas de lactentes, crianças pequenas ou figuras humanizadas. No total, 40,6\% (n=13) fórmulas exibiam ilustrações que faziam alusão à alimentação artificial pela mãe, sendo todas da mesma marca comercial.

Expressões que indicam superioridade do produto foram identificadas em $65,6 \%$ (n=21) dos produtos, além de indicarem falso conceito de vantagem, como por exemplo: "Premium", "Supreme" e "ProExpert". Essas expressões sugerem forte semelhança com o leite materno, o que contraria o item 4.3.2. da RDC no $222 / 2002^{8}$ e o inciso II do artigo 10 da Lei 11.265/2006 ${ }^{9}$.

Com relação às exigências de promoção comercial das fórmulas infantis, todos os produtos apresentam pelo menos uma inadequação à legislação. Contudo, nenhuma delas apresentou frases ou expressões que possam colocar em dúvida a capacidade da lactante de amamentar; todas tinham advertências sobre os riscos de preparo inadequado e instruções; orientações sobre a dosagem para diluição, uso, preparo, conservação e medidas de higiene, incluindo as mãos, superfícies de trabalho à preparação do produto pronto e necessidade de esterilização dos utensílios.

Todas as fórmulas infantis ao serem pesquisadas via websites apresentavam promoções comerciais indevidas, assim como o de outros produtos da mesma marca, violando o item 4.1 da Resolução RDC n. ${ }^{\mathrm{o}}$ 222/2002 ${ }^{8}$. Entretanto, nos estabelecimentos comerciais visitados não houve irregularidades.

Quanto à advertência obrigatória ${ }^{12}$ nos rótulos das fórmulas: "Aviso importante: Este produto somente deve ser usado na alimentação de crianças menores de 1 (um) ano de idade com indicação expressa de médico ou nutricionista. $\mathrm{O}$ aleitamento materno evita infecções e alergias e fortalece o vínculo mãe-filho", 68,7\% (n=22) delas não o apresentavam no painel principal como as leis exigem e $93,7 \%$ fórmulas $(n=30)$ não apresentavam o tamanho da fonte adequado (mesmo tamanho da letra de denominação de venda do produto).

Na figura 1 há o sumário das irregularidades encontradas, das Fórmulas Infantis para Lactente e Fórmulas Infantis de Seguimento para Lactente e de Crianças de Primeira Infância. 


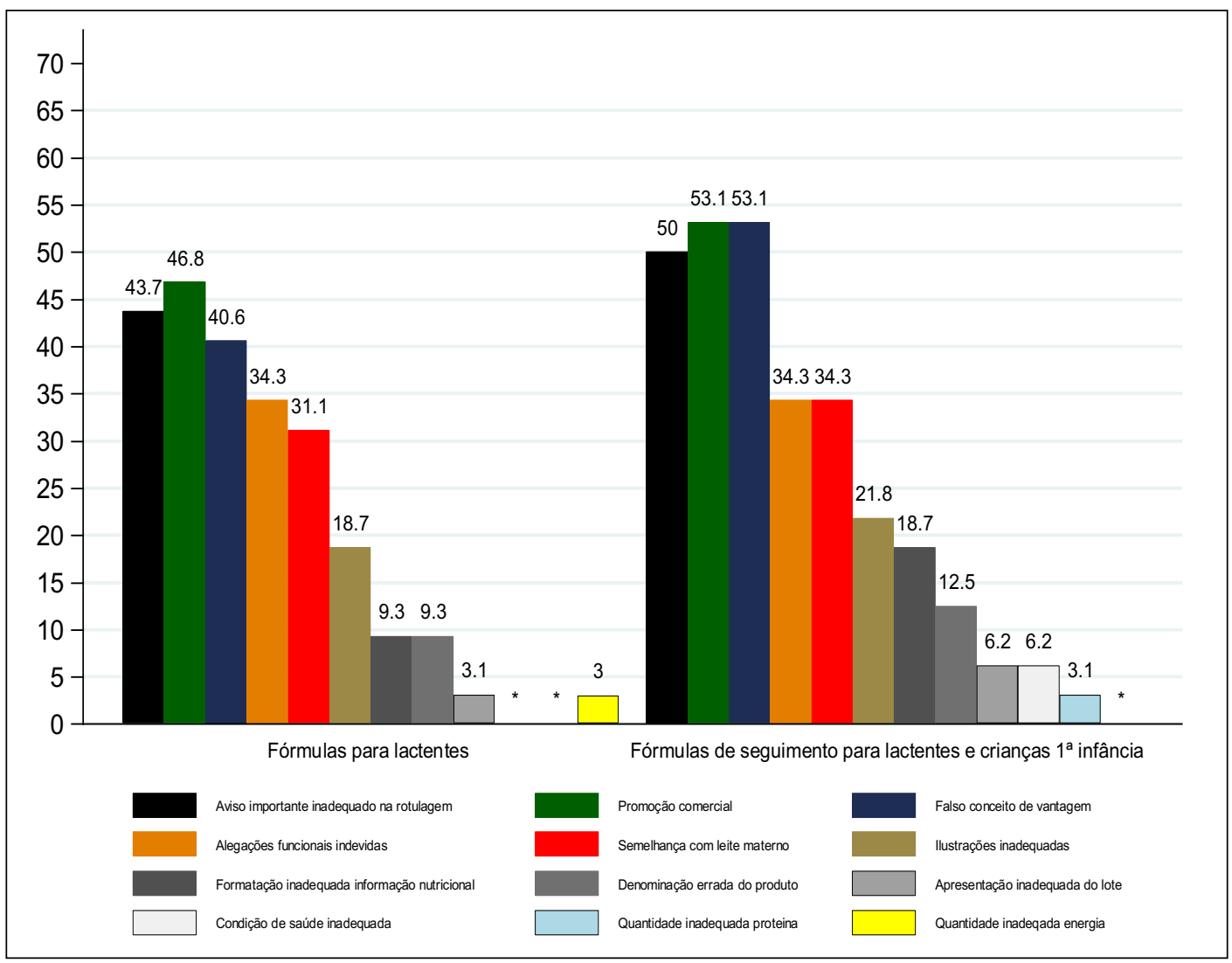

*valor igual a zero

Figura 1. Irregularidades (\%) de rotulagem e promoção comercial nas fórmulas infantis para lactente $(\mathrm{n}=15)$ e das fórmulas infantis de seguimento para lactentes e de crianças de primeira infância $(\mathrm{n}=17)$.

\section{Discussão}

Os itens com maior frequência de inconformidades nos produtos analisados se concentram na informação nutricional, em quesitos de rotulagem geral, falso conceito de vantagem e/ou segurança, venda comercial e quanto ao modo de apresentação de uma advertência exigida no quesito promoção comercial.

Com relação à rotulagem geral, as resoluções dizem sobre expressões que podem ser complementadas na designação do produto à fórmula que seja à base de proteína do leite de vaca ou à proteína à base de soja..$^{13,14}$ No caso da proteína do leite de vaca, foram encontrados os termos 
“com proteínas lácteas" e “com proteínas lácteas parcialmente hidrolisadas”, quando o correto é “à base de leite de vaca". ${ }^{13,14}$ Estes termos técnicos podem dificultar a compreensão do consumidor sobre os componentes do produto.

No que diz respeito aos itens sobre promoção comercial, as irregularidades se concentraram na presença de ilustrações que remetem o consumidor a relação de cuidado da mãe com o filho (um pássaro alimentando e cuidando de seus dois filhotes) em todas as fórmulas de uma das marcas comerciais selecionadas. A Lei n.․ 11.265/2006 e a Resolução RDC no 222/2002 proíbem qualquer tipo de figuras que não sejam aquelas necessárias para ilustrar métodos de preparação ou uso do produto, com exceção da logomarca. A mesma imagem foi observada em 10 fórmulas infantis no total de 16 analisadas no estudo de Silva et al, ${ }^{22}$ o que mostra que não houve progresso até o momento quanto a adequação deste item.

Não foram encontradas expressões como "leite humanizado", "leite maternizado" e "substituto do leite materno", porém existiam palavras perto do nome fantasia que tem o intuito de sugerir vantagens e/ou superioridade a outras marcas ou até mesmo ao leite materno como "Supreme", "Comfor", "Premium", "Premium+", "Pro-Expert" e "Pro-Futura". Em estudos anteriores esses termos não foram considerados como expressões que sugerem vantagem. ${ }^{23,24}$ Embora não haja citação desses termos na legislação, entende-se que os termos são usados com a intenção de indicar superioridade do produto.

Outra afirmação que pode sugerir superioridade do produto é a presença de alegação de propriedade funcional no rótulo, a qual não é permitida. ${ }^{13,14}$ Neste estudo foi verificado irregularidade no tamanho da letra, realce e destaque diferentes da designação do produto para fórmulas com DHA, ARA, taurina, FOS/GOS, nucleotídeos e probióticos. ${ }^{9}$ Em duas fórmulas identificou-se destaque à presença de luteína, sendo que este composto não está na lista de nutrientes que podem ser destacados no rótulo. ${ }^{12-14}$ Caso seja alegado na rotulagem de alimentos, é necessário que sua quantidade, pronta para consumo, esteja próxima à alegação e que tenha respaldo científico sobre o seu uso ${ }^{25,26}$ e tais critérios não foram encontrados. A presença de alegações funcionais também foi encontrada nas fórmulas infantis para lactentes e fórmulas infantis de seguimento para lactentes em estudo anterior, ${ }^{24}$ no qual os autores afirmam que o uso de tais alegações pode deixar subtendido que o crescimento e desenvolvimento do lactente só será possível por conter essas alegações nos produtos.

No que tange à presença de palavras que podem indicar promoção de saúde para os lactentes e crianças, identificou-se a presença das expressões "Active" e "Sensitive" que estão em oposição ao inciso VI do Art. 10 da Lei 11.265/2006 ${ }^{9}$. No caso da fórmula que apresentava a palavra "Active", ao lado possuía a alegação de "prebióticos" que sugere resolver o problema intestinal do lactente. A fórmula que tinha a palavra "Sensitive" tinha o complemento "com proteína parcialmente hidrolisada", que pressupõe resolver o problema de absorção do nutriente para lactentes com o sistema digestório ainda em desenvolvimento. 
Ainda baseado ao falso conceito de vantagem e segurança, em uma única fórmula infantil estava escrito "... é uma fórmula infantil desenvolvida para lactentes desde o nascimento até os 6 meses de vida”, o que contraria o item 4.3.4 da RDC 222/2002. ${ }^{8}$ Um estudo realizado em 2008 encontrou a mesma irregularidade. ${ }^{22}$

Todas as fórmulas apresentam a advertência obrigatória ${ }^{6}$ sobre recomendação do uso da formula por médico ou nutricionista e sobre os benefícios do leite materno. As irregularidades verificadas nos produtos se concentraram na formatação inadequada quanto aos caracteres idênticos e com o mesmo tamanho da letra da designação de venda como determina a Lei 11.474/2007. ${ }^{11}$ No estudo de Silva et al. ${ }^{22}$ e de Chater ${ }^{24}$ também não houve o devido cuidado ao modo de apresentação, deixando a advertência sem destaque, o que revela o não progresso nesta questão ao longo desses anos.

Um ponto relevante a ser destacado e comemorado com o avanço da NBCAL no Brasi,l visualizado na análise dos produtos, foi a ausência de frases ou expressões que possam por em dúvida a capacidade das mães de amamentarem seus filhos (RDC n.o 222/2002; Lei 11.265/20069); às advertências sobre os riscos do preparo inadequado e instruções para a correta preparação do

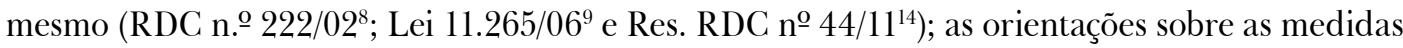
de higiene a serem observadas e a dosagem para a diluição, se necessário (RDC n.o 222/20028; Lei 11.265/2006 ${ }^{9}$ ); as instruções adequadas de uso, preparo e conservação do produto, incluindo informações sobre higiene das mãos e superfícies de trabalho e necessidade de esterilização dos utensílios (RDC nº 44/2011 ${ }^{14}$ ).

Em comparação com a literatura, ${ }^{22,24,27-29}$ os itens de promoção comercial estão se adequando às legislações, porém de forma mais lenta que os de regulamento técnico a respeito da rotulagem geral e nutricional. O estudo de Cyrillo et al ${ }^{30}$ diz que o conhecimento da Norma Brasileira de Comercialização de Alimentos para Lactentes, até mesmo entre profissionais da saúde, é restrito. Embora este estudo tenha sido realizado na década anterior, é possível que a prescrição destes produtos pelos profissionais ainda persista. Entretanto, um ponto relevante a ser analisado é a distribuição de amostras grátis de fórmulas infantis para esses profissionais, o que também é proibido pela NBCAL.

Acredita-se que uma das principais limitações do nosso trabalho seja a ausência de análise nos quesitos redução de preços, venda casada, destaque dos produtos em prateleiras nos estabelecimentos comerciais visitados. Estes itens devem ser analisados, pois o preço é um dos itens que facilitam a compra desses produtos, especialmente por serem produtos com elevado custo e com elevada demanda de consumo por lactentes e crianças de primeira infância. Adicionalmente, é necessário investigar e conhecer o entendimento das mães sobre os rótulos dessas fórmulas.

A partir dos resultados observados no presente estudo pode-se afirmar que as rotulagens geral e nutricional propostas na NBCAL estão sendo respeitadas, salvo pequenas irregularidades. Entretanto, alertamos para as inconformidades na promoção comercial ainda presente nos produtos 
das fórmulas infantis. É relevante destacar que o cerne da NBCAL é a proteção da mãe quanto às propagandas das fórmulas, que possam confundi-la quanto a superioridade do leite materno e é justamente este quesito que foi mais violado nos produtos.

\section{Agradecimentos}

Ao Conselho Nacional de Desenvolvimento Científico e Tecnológico (CNPq), que, pelo Programa Institucional de Bolsas Iniciação Científica Voluntária (PIVIC) (edital no 01/2016), propiciou a realização deste trabalho à Mariana Morais Baldani.

\section{Colaboradores}

Baldani MM realizou a coleta de dados, análise dos dados e redigiu o manuscrito; Pascoal GB contribuiu na redação do manuscrito e na revisão final e Rinaldi AEM foi responsável pela concepção do objetivo do trabalho, orientou a coleta e análise dos dados, contribuiu na redação e revisão final do manuscrito.

Conflito de interesses: Os autores declaram não haver conflito de interesses.

\section{Referências}

1. Organização Mundial da Saúde. Código Internacional de Comercialização de Substitutos do Leite Materno. Geneva: WHO; 1981.

2. Organização Mundial da Saúde. Fundo das Nações Unidas para a Infância. Reunião conjunta sobre alimentação de lactentes e crianças na primeira infância: declaração, recomendações e relação dos participantes. Genebra: WHO; 1979. Suíça: UNICEF; 1980.

3. Brasil. Ministério da Saúde. Pesquisa nacional de demografia e saúde da criança e da mulher - PNDS 2006: dimensões do processo reprodutivo e da saúde da criança. Brasília: Ministério da Saúde; 2009.

4. Brasil. Agência Nacional de Vigilância Sanitária. Resolução no 31, de 12 de outubro de 1992. Norma Brasileira para a Comercialização de Alimentos para Lactentes. Diário Oficial da União. 13 nov. 1992; Seção 1.

5. Brasil. Agência Nacional de Vigilância Sanitária. Promoção Comercial dos Produtos Abrangidos pela NBCAL [Internet]. Brasília: Anvisa. [acesso em: 23 jan. 2018]. Disponível em: http://www.anvisa. gov.br/propaganda/cartilha_nbcal.pdf

6. Brasil. Agência Nacional de Vigilância Sanitária. Portaria no 29, de 13 de janeiro de 1998. A Secretária de Vigilância do MS aprova o Regulamento Técnico referente a Alimentos para Fins Especiais. Diário Oficial da União. 14 jan. 1998; Seção 1. 
Demetra: alimentaÇÃo, NUTRiÇÃo \& SAÚde

7. Brasil. Agência Nacional de Vigilância Sanitária. Resolução no 221, de 05 de agosto de 2002. Regulamento Técnico para sobre Chupetas, Bicos, Mamadeiras e Protetores de Mamilo. Diário Oficial da União. 06 ago. 2002; Seção 1.

8. Brasil. Agência Nacional de Vigilância Sanitária. Resolução no 222, de 05 de agosto de 2002. Regulamento Técnico para a Promoção Comercial dos Alimentos para Lactentes e Crianças de Primeira Infância. Diário Oficial da União. 06 ago. 2002; Seção 1.

9. Brasil. Lei no 11.265, de 3 de janeiro de 2006. O Congresso Nacional Regulamenta a Comercialização de Alimentos para Lactentes e Crianças de Primeira Infância e também a de Produtos de Puericultura Correlatos. Diário Oficial da União. 04 jan. 2006; Seção 1.

10. Rede Internacional em Defesa do Direito de Amamentar - International Baby Food Action Network. IBFAN Brasil [Internet]. [acesso em: 04 mar. 2017]. Disponível em: http://www.ibfan.org.br/site/

11. World Health Organization. Marketing of breast-milk substitutes: National Implementation of the International Code. Status report 2016. Genebra: WHO; UNICEF; IBFAN; 2016. viii,64 p.

12. Brasil. Agência Nacional de Vigilância Sanitária. Resolução no 42, de 19 de setembro de 2011. Regulamento Técnico de Compostos de Nutrientes para Alimentos Destinados a Lactentes e a Crianças de Primeira Infância. Diário Oficial da União. 20 set. 2011; Seção 1.

13. Brasil. Agência Nacional de Vigilância Sanitária. Resolução no 43, de 19 de setembro de 2011. Regulamento Técnico para Fórmulas Infantis para Lactentes. Diário Oficial da União. 20 set. 2011; Seção 1.

14. Brasil. Agência Nacional de Vigilância Sanitária. Resolução no 44, de 19 de setembro de 2011. Regulamento Técnico para Fórmulas Infantis de Seguimento para Lactentes e Crianças de Primeira Infância. Diário Oficial da União. 20 set. 2011; Seção 1.

15. Brasil. Agência Nacional de Vigilância Sanitária. Resolução no 46, de 19 de setembro de 2011. Aditivos Alimentares e Coadjuvantes de Tecnologia para Fórmulas Infantis Destinadas a Lactentes e Crianças de Primeira Infância. Diário Oficial da União. 20 set. 2011; Seção 1.

16. Brasil. Agência Nacional de Vigilância Sanitária. Resolução no 27, de 6 de agosto de 2010. Categorias de Alimentos e Embalagens Isentos e com Obrigatoriedade de Registro Sanitário. Diário Oficial da União. 28 ago. 2010; Seção 1.

17. Brasil. Agência Nacional de Vigilância Sanitária. Resolução no 259, de 20 de setembro de 2002. Regulamento Técnico sobre Rotulagem de Alimentos Embalados. Diário Oficial da União. 21 set. 2002; Seção 1.

18. Brasil. Agência Nacional de Vigilância Sanitária. Resolução no 360, de 23 de dezembro de 2003. Aprova Regulamento Técnico sobre Rotulagem Nutricional de Alimentos Embalados, tornando obrigatória a rotulagem nutricional. Diário Oficial da União. 24 dez. 2003; Seção 1.

19. Brasil. Agência Nacional de Vigilância Sanitária. Instituto Nacional de Meteorologia, Normalização e Qualidade Industrial (INMETRO). Portaria no 157, de 19 de agosto de 2002. Aprova o Regulamento Técnico Metrológico Estabelecendo a Forma de Expressar o conteúdo Líquido a ser Utilizado nos Produtos Pré-Medidos. Diário Oficial da União. 20 ago. 2002; Seção 1. 
20. Brasil. Lei $\mathrm{n}^{\circ}$ 10.674, de 16 de maio de 2003. O Congresso Nacional Obriga que os Produtos Alimentícios Comercializados Informem sobre a Presença de Glúten. Diário Oficial da União. 17 maio 2003; Seção 1.

21. Brasil. Lei no 11.474, de 15 de maio de 2007. O Congresso Nacional Regulamenta a Comercialização de Alimentos para Lactentes e Crianças de Primeira Infância e também a de Produtos de Puericultura Correlatos, e dá outras Providências. Diário Oficial da União. 16 maio 2007; Seção 1.

22. Silva AS, Dias MRM, Ferreira TAPC. Rotulagem de alimentos para lactentes e crianças de primeira infância. Rev Nutr. 2008; 2(12):185-194.

23. Abrantes VRS, Tabai KC. Fórmulas para o público infantil: a promoção comercial nas rotulagens de fórmulas infantis e sua adequação com a legislação vigente. Oikos: Revista Brasileira de Economia Doméstica; 2013; 24(1):21-37.

24. Chater MMF. Rotulagem de produtos destinados a lactentes e crianças de primeira infância. Brasília. Monografia [Especialização em Qualidade de Alimentos]. Brasília: Universidade de Brasília; 2009.

25. Brasil. Agência Nacional de Vigilância Sanitária. Resolução no 18, 30 de abril de 1999. Regulamento Técnico que Estabelece as Diretrizes Básicas para Análise e Comprovação de Propriedades Funcionais e ou de Saúde Alegadas em Rotulagem de Alimentos. Diário Oficial da União. 01 maio 1999; Seção 1.

26. Brasil. Agência Nacional de Vigilância Sanitária. Resolução no 2, de 07 de janeiro de 2002. Aprova o Regulamento Técnico de Substâncias Bioativas e Probióticos Isolados com Alegação de Propriedades Funcional e ou de Saúde. Diário Oficial da União. 09 jan. 2002.

27. Rea MF, Toma TS. Rótulos de alimentos infantis: alguns aspectos das práticas de marketing no Brasil. Rev Nutr. 1997; 10(2):127-135.

28. Monteiro R. Norma brasileira de comercialização de alimentos para lactentes e crianças de primeira infância: histórico, limitações e perspectivas. Rev Panam Salud Pública. 2006; 19(5):354-361.

29. Rocha KF. Análise da rotulagem de fórmulas infantis para lactentes. Trabalho de Conclusão de Curso [Graduação em Nutrição]. [Natal]: Universidade Federal do Rio Grande do Norte; 2016.

30. Cyrillo DC, Sarti FM, Farina EMQ, Mazzon JA. Duas décadas da norma brasileira de comercialização de alimentos para lactentes: há motivos para comemorar? Rev Panam Salud Pública. 2009; 25(2):134-140.

Recebido: 23 de fevereiro, de 2018

Revisado: 04 de maio, de 2018

Aceito: 11 de junho de 2018 
